\title{
Urinary Neutrophil Gelatinase- Associated Lipocalin in Children with Idiopathic Nephrotic Syndrome: A Biomarker to Differentiate Between Steroid Sensitive and Resistant Forms of Disease
}

\author{
Om P Mishra ${ }^{1 *}$, Santosh K Mehta ${ }^{1}$, Pradeep Srivastava ${ }^{2}$, Abhishek Abhinay ${ }^{1}$, Rajniti Prasad ${ }^{1}$ and Vineeta V Batra ${ }^{3}$ \\ ${ }^{1}$ Division of Pediatric Nephrology, Department of Pediatrics, Institute of Medical Sciences, Banaras Hindu University, Varanasi, India \\ ${ }^{2}$ Department of Biochemical Engineering, Indian Institute of Technology, Banaras Hindu University, Varanasi, India \\ ${ }^{3}$ Department of Pathology, G.B. Pant Hospital, New Delhi, India
}

\begin{abstract}
Background: Objectives of the study were to find out the ability of urinary neutrophil gelatinase- associated lipocalin (NGAL) as a biomarker to differentiate between steroid resistant nephrotic syndrome (SRNS) and steroid sensitive nephrotic syndrome (SSNS), and also to observe variation in levels, if any, between focal segmental glomerulosclerosis (FSGS) and minimal change disease (MCD) in SRNS patients.

Methods: The study included 63 patients of idiopathic nephrotic syndrome (19 SSNS in relapse, 19 SSNS in remission and 25 SRNS), aged 2.5-16 years, along with 17 controls. Urinary NGAL was measured by ELISA and the values were normalised with urinary creatinine.

Results: Median urinary NGAL/creatinine level was significantly raised in SRNS as compared to SSNS relapse, SSNS remission and controls $(p<0.001)$. A cut-off level of NGAL/creatinine $>18.3 \mathrm{ng} / \mathrm{mg}$ had sensitivity of $84 \%$, specificity of $97.4 \%$ and area under the curve of 0.935 ( $p<0.001,95 \%$ confidence interval $0.871-0.998)$ to differentiate SRNS from SSNS patients. Median urinary NGAL/creatinine value was significantly raised in children with FSGS as compared to MCD $(p=0.003)$ in SRNS patients. It had significant positive correlations with duration of illness $(r=0.342, p=0.006)$, urine protein creatinine ratio $(r=0.594, p<0.001)$ and negative correlation with serum albumin $(r=0.470, p<0.001)$.
\end{abstract}

Conclusion: Urinary NGAL/creatinine level correlated with activity of the disease and it can distinguish not only SRNS from SSNS but also FSGS and MCD histopathological sub-types of SRNS in children.

Keywords: Neutrophil gelatinase-associated lipocalin; Idiopathic nephrotic syndrome; Focal segmental glomerulosclerosis; Minimal change disease

\section{Introduction}

Nephrotic Syndrome is one of the most common renal disorders in pediatric population. About $90 \%$ of the cases in children are idiopathic and steroid sensitive nephrotic syndrome (SSNS) with a favourable prognosis [1], while the remaining $10 \%$ do not respond to steroid and are classified as steroid resistant nephrotic syndrome (SRNS). The clinical presentations of SSNS and SRNS patients are often same and there are no specific laboratory markers which can distinguish reliably between the two clinical entities. Invasive diagnostic renal biopsy remains the method of choice to differentiate between these two clinical forms of disease. However, children with nephrotic syndrome are not usually biopsied unless they have atypical features and/or steroid resistance. Minimal change disease (MCD) and focal segmental glomerulosclerosis (FSGS) are the two common histopathological lesions and the latter having unfavourable long-term prognosis and often progresses to chronic kidney disease. Urine has been said as fluid biopsy of kidney and urogenital tract and the changes may reflect in urine as a biomarker which can be detected.

Human neutrophil gelatinase-associated lipocalin (NGAL) has been identified as a protein covalently bound to gelatinase from neutrophils. During kidney development, NGAL promotes epithelial differentiation of the mesenchymal progenitors, leading to the generation of glomeruli, proximal tubules, Henle's loop and distal tubules. NGAL is expressed in neutrophils and various epithelia, especially in the distal nephron segments of the kidney [2]. Its expression is rapidly up regulated in response to renal injury and has been proven to be a sensitive biomarker for early detection of acute kidney injury [3-5]. The utility of NGAL as a marker of chronic kidney disease progression has been also reported [6,7]. In the recent past, it has been shown that urinary NGAL has differentiating ability for SRNS patients from SSNS with wide variability in sensitivity and specificity [8-12]. Further, Youssef et al. [13] found that urine NGAL was elevated in the FSGS group as compared to controls. However, previous studies have not demonstrated its ability to differentiate between FSGS and MCD patients, which differ in tubular dysfunction, response to therapy and outcome.

In view of these observations, the present study was undertaken with primary objective to find out the ability of urinary NGAL as a biomarker to differentiate between SSNS and SRNS patients and also variation in levels, if any, among clinical MCD, biopsy proven MCD and FSGS cases as a secondary outcome measure.

*Corresponding author: Om P Mishra, In-Charge, Division of Pediatric Nephrology, Department of Pediatrics, Institute of Medical Sciences, Banaras Hindu University, Varanasi, India, Tel +91-542-2317111; Fax +91-542-2367568; E-mail: opmpedia@yahoo.co.uk

Received February 15, 2018; Accepted February 26, 2018; Published February 28, 2018

Citation: Mishra OP, Mehta SK, Srivastava P, Abhinay A, Prasad R, et al. (2018) Urinary Neutrophil Gelatinase- Associated Lipocalin in Children with Idiopathic Nephrotic Syndrome: A Biomarker to Differentiate Between Steroid Sensitive and Resistant Forms of Disease. J Mol Biomark Diagn 9: 383. doi: 10.4172/2155 9929.1000383

Copyright: ( 2018 Mishra OP, et al. This is an open-access article distributed under the terms of the Creative Commons Attribution License, which permits unrestricted use, distribution, and reproduction in any medium, provided the original author and source are credited. 
Citation: Mishra OP, Mehta SK, Srivastava P, Abhinay A, Prasad R, et al. (2018) Urinary Neutrophil Gelatinase- Associated Lipocalin in Children with Idiopathic Nephrotic Syndrome: A Biomarker to Differentiate Between Steroid Sensitive and Resistant Forms of Disease. J Mol Biomark Diagn 9: 383. doi: 10.4172/2155-9929.1000383

\section{Materials and Methods}

The study enrolled 63 patients of idiopathic nephrotic syndrome (25 sporadic steroid resistant and 19 steroid sensitive in relapse and 19 steroid sensitive in remission), in the age group 2.5-16 years during the period of July 2015 to September 2016. They were selected from those admitted to and/or attending the Division of Pediatric Nephrology Clinic of the Department of Pediatrics. Another 17 healthy children in the same age group of both gender attending the general pediatric outpatient department for routine health check-up were included as controls group. The diagnosis of idiopathic nephrotic syndrome was based on the presence of generalised edema, proteinuria (proteinuria ++ or more by heat precipitation method and /or spot urine protein/ creatinine ratio of $>2 \mathrm{mg} / \mathrm{mg}$ ), hypoalbuminemia (serum albumin $<2.5 \mathrm{~g} / \mathrm{dl}$ ), hypercholesterolemia (serum cholesterol $>200 \mathrm{mg} / \mathrm{dl}$ ) and without any systemic disease known to produce nephrotic syndrome. Children with congenital nephrotic syndrome (onset of disease before 3 months of age), secondary causes of nephrotic syndrome (HIV nephropathy, Hepatitis B nephropathy, Lupus nephritis, Henoch Schonlein purpura), patients with urinary tract infection and those on nephrotoxic medications such as vancomycin, aminoglycosides, non-steroidal inflammatory drugs and angiotensin converting enzyme inhibitors were excluded. The study protocol was approved by Institute Ethical Committee and informed consent was obtained from the parents or legal representatives of all children.

Patients were treated as per Indian Society of Pediatric Nephrology recommendations $[14,15]$. They were categorized depending upon the response to steroid therapy. Cases were defined as SSNS who achieved remission (urine protein negative by heat precipitation method and/ or urine protein/ creatinine ratio of $<0.2 \mathrm{mg} / \mathrm{mg}$ for three consecutive days) with prednisolone $\left(60 \mathrm{mg} / \mathrm{m}^{2} /\right.$ day as a single oral dose) by 4 weeks of therapy, and patients who did not achieve remission with this treatment were categorized as SRNS. Relapse was defined as patients having proteinuria $2+$ or more by heat precipitation test and/or spot urine protein/ creatinine ratio of $>2 \mathrm{mg} / \mathrm{mg}$ for three consecutive days, having previously been in remission. Renal biopsy was not done in children with SSNS as they had no persistent gross/microscopic hematuria, hypertension, azotemia and were steroid responsive suggestive of clinical MCD, while it was performed in SRNS patients and the tissues were examined under both light and immunofluorescent microscopy by the same renal pathologist.

\section{Urine NGAL assay}

Urine samples were collected before the start of prednisolone in cases of relapse, and patients in remission when they were either offsteroid in infrequent relapsers or on low dose alternate day's treatment in frequent relapsers. In steroid resistant cases, samples were collected after renal biopsy but before start of drugs such as calcineurin inhibitors or mycophenolate mofetil. Samples were collected in a sterile container and centrifuged at $1500 \mathrm{X} \mathrm{g}$ at $4^{\circ} \mathrm{C}$ for 15 minutes and supernatant was stored at $-80^{\circ} \mathrm{C}$ until assay. NGAL estimation was done using commercially available ELISA kit (KTR-883, Epitope Diagnostics, Inc. San Diego, USA) in the Department of Biochemical Engineering.

\section{Statistical analysis}

Data were analysed using SPSS version 20.0 software. Analysis of variance (ANOVA) was applied for comparison among groups showing Gaussian distribution and Kruskal Wallis test for nonGaussian distribution. For post-hoc analysis, Student-Neumans-Keul and Mann-Whitnay $U$ tests were applied, respectively. Chi-square test was used for comparison of proportions. The values of NGAL were normalized with urine creatinine and expressed as NGAL/creatinine (ng/mg). Receiver operating characteristic curve (ROC) was generated to find out the cut-off level of urinary NGAL /creatinine to distinguish between SRNS from SSNS. The Spearman's rho correlation coefficients were calculated between urinary NGAL/creatinine with other parameters. A p-value of $<0.05$ was considered as significant.

\section{Results}

The basic characteristics of study subjects are presented in Table 1. Children with SSNS relapse and SRNS had significantly lower mean serum total protein, albumin and higher serum cholesterol levels in comparison to controls. The values did not differ significantly between controls and SSNS remission. Other parameters such as age, gender, weight, height, systolic and diastolic blood pressure, estimated glomerular filtration rate (eGFR), serum sodium, potassium and creatinine were comparable among different groups.

Table 2 shows duration of illness and different urinary parameters of study subjects, and it was observed that SRNS patients had significantly longer duration of illness than SSNS relapse and SSNS remission. The SRNS group had significantly lower median urine creatinine and higher protein creatinine ratio as compared to controls, SSNS relapse and SSNS remission. The median urine NGAL and NGAL creatinine ratios followed similar pattern and were significantly raised in SSNS relapse and SRNS as compared to controls and SSNS remission. Further, patients of SRNS had significantly higher median urinary NGAL/creatinine level than SSNS relapse (Figure 1).

The receiver operating characteristic curve (ROC) was also

\begin{tabular}{|c|c|c|c|c|c|}
\hline Parameters & $\begin{array}{c}\text { Controls } \\
n=17\end{array}$ & $\begin{array}{l}\text { SSNS } \\
\text { relapse } \\
n=19\end{array}$ & $\begin{array}{c}\text { SSNS } \\
\text { remission } \\
n=19\end{array}$ & $\begin{array}{c}\text { SRNS } \\
n=25\end{array}$ & $p$ value \\
\hline Age (years) ${ }^{d}$ & $\begin{array}{c}8.0(5.0 \\
10.5)\end{array}$ & $\begin{array}{c}5.0(3.0 \\
9.0)\end{array}$ & $6.0(3.0,8.0)$ & $\begin{array}{c}7.0(3.0 \\
10.0)\end{array}$ & $0.174^{a}$ \\
\hline $\begin{array}{l}\text { Gender (Male/ } \\
\text { Female) }\end{array}$ & $14 / 3$ & $12 / 7$ & $14 / 5$ & $14 / 11$ & $0.294^{b}$ \\
\hline Weight (kg) & $22.4 \pm 5.6$ & $19.6 \pm 8.6$ & $18.7 \pm 5.2$ & $22 \pm 9.2$ & $0.258^{c}$ \\
\hline Height (cm) & $121.7 \pm 17.2$ & $\begin{array}{c}104.9 \pm \\
20.3\end{array}$ & $\begin{array}{c}108.6 \pm \\
15.4\end{array}$ & $\begin{array}{c}114.8 \pm \\
26.3\end{array}$ & $0.090^{c}$ \\
\hline $\begin{array}{l}\text { Systolic blood } \\
\text { pressure }(\mathrm{mm} \\
\mathrm{Hg})\end{array}$ & $103.1 \pm 10.9$ & $100.5 \pm 6.6$ & $100.0 \pm 6.6$ & $107.6 \pm 9.6$ & $0.08^{c}$ \\
\hline $\begin{array}{l}\text { Diastolic blood } \\
\text { pressure }(\mathrm{mm} \\
\mathrm{Hg})\end{array}$ & $68.1 \pm 8.8$ & $66.3 \pm 9.1$ & $67.8 \pm 8.4$ & $73.4 \pm 11.8$ & $0.085^{c}$ \\
\hline $\begin{array}{l}\text { eGFR }(\mathrm{ml} / \\
\left.\mathrm{min} / 1.73 \mathrm{~m}^{2}\right)\end{array}$ & $123.1 \pm 30.7$ & $\begin{array}{c}107.4 \pm \\
23.7\end{array}$ & $115.7 \pm 17.9$ & $\begin{array}{c}135.9 \pm \\
49.8\end{array}$ & $0.058^{c}$ \\
\hline $\begin{array}{l}\text { Serum sodium } \\
(\mathrm{mEq} / \mathrm{l})\end{array}$ & $138.9 \pm 3.5$ & $136 \pm 5.4$ & $137 \pm 4.9$ & $136 \pm 6.4$ & $0.297^{c}$ \\
\hline $\begin{array}{l}\text { Serum } \\
\text { potassium } \\
(\mathrm{mEq} / \mathrm{l})\end{array}$ & $4.4 \pm 0.6$ & $4.3 \pm 0.8$ & $4.5 \pm 0.6$ & $4.3 \pm 0.8$ & $0.853^{c}$ \\
\hline $\begin{array}{c}\text { Serum } \\
\text { creatinine }(\mathrm{mg} / \\
\mathrm{dl})^{d}\end{array}$ & $0.5(0.4,0.6)$ & $0.5(0.4,0.6)$ & $0.6(0.4,0.7)$ & $0.5(0.4,0.6)$ & $0.348^{a}$ \\
\hline $\begin{array}{l}\text { Serum total } \\
\text { protein }(\mathrm{g} / \mathrm{dl})\end{array}$ & $6.8 \pm 0.5$ & $4.6 \pm 0.8$ & $6.5 \pm 0.8$ & $4.3 \pm 1.3$ & $<0.001^{c}$ \\
\hline $\begin{array}{l}\text { Serum albumin } \\
(\mathrm{g} / \mathrm{dl})\end{array}$ & $3.6 \pm 0.6$ & $2.0 \pm 0.6$ & $3.7 \pm 0.5$ & $1.8 \pm 0.5$ & $<0.001^{\mathrm{c}}$ \\
\hline $\begin{array}{c}\text { Serum } \\
\text { cholesterol (mg/ } \\
\text { dl) }\end{array}$ & $\begin{array}{c}140.9 \pm \\
30.7\end{array}$ & $\begin{array}{c}457.3 \pm \\
169.1\end{array}$ & $\begin{array}{c}154.1 \pm \\
44.5\end{array}$ & $\begin{array}{c}516.8 \pm \\
169.7\end{array}$ & $<0.001^{\mathrm{c}}$ \\
\hline
\end{tabular}

Note: $\mathrm{n}$ - numbers of cases, a- Kruskal Wallis test, b- Chi-square test, c- Analysis of variance, $d$ - Data are median and inter quartile range in parentheses, SSNSSteroid sensitive nephrotic syndrome, SRNS-Steroid resistant nephrotic syndrome

Table 1: Basic characteristics of study subjects. 
Citation: Mishra OP, Mehta SK, Srivastava P, Abhinay A, Prasad R, et al. (2018) Urinary Neutrophil Gelatinase- Associated Lipocalin in Children with Idiopathic Nephrotic Syndrome: A Biomarker to Differentiate Between Steroid Sensitive and Resistant Forms of Disease. J Mol Biomark Diagn 9: 383. doi: 10.4172/2155-9929.1000383

Page 3 of 5

\begin{tabular}{|c|c|c|c|c|c|c|}
\hline Parameters* & (a)Controls $n=17$ & (b) SSNS relapse $n=19$ & (c) SSNS remission $n=19$ & (d) SRNS n=25 & p value ${ }^{* *}$ & Differences $p$ values ${ }^{\star \star *}$ \\
\hline \multirow{2}{*}{ Duration of illness (months) } & \multirow{2}{*}{ - } & \multirow{2}{*}{$16(11.0,32.0)$} & \multirow{2}{*}{$19(10.0,23.0)$} & \multirow{2}{*}{$29(20.5,41.0)$} & \multirow{2}{*}{0.001} & b vs $d=0.009$ \\
\hline & & & & & & c vs $d=0.001$ \\
\hline \multirow{3}{*}{ Urinary creatinine $(\mathrm{mg} / \mathrm{dl})$} & \multirow{3}{*}{$126.6(94.9,154.1)$} & \multirow{3}{*}{$135(110.6,149.4)$} & \multirow{3}{*}{$122.4(102.7,152)$} & \multirow{3}{*}{$95.6(77.2,113.5)$} & \multirow{3}{*}{0.001} & a vs $\mathrm{d}=0.009$ \\
\hline & & & & & & b vs $d=0.001$ \\
\hline & & & & & & c vs $d=0.001$ \\
\hline \multirow{5}{*}{$\begin{array}{l}\text { Urinary protein creatinine } \\
\text { ratio }(\mathrm{mg} / \mathrm{mg})\end{array}$} & \multirow{5}{*}{$0.4(0.3,0.8)$} & \multirow{5}{*}{$13.5(7.0,20.6)$} & \multirow{5}{*}{$0.7(0.3,1.0)$} & \multirow{5}{*}{$22.7(10.8,37.9)$} & \multirow{5}{*}{$<0.001$} & a vs $b<0.001$ \\
\hline & & & & & & a vs $d<0.001$ \\
\hline & & & & & & b vs $c<0.001$ \\
\hline & & & & & & b vs $d=0.019$ \\
\hline & & & & & & c vs $d<0.001$ \\
\hline \multirow{6}{*}{ Urinary NGAL (ng/ml) } & \multirow{6}{*}{$8.8(6.0,10.0)$} & \multirow{6}{*}{$16.8(15.2,18.2)$} & \multirow{6}{*}{$11.4(10.2,12.8)$} & \multirow{6}{*}{$22.1(18.4,26.5)$} & \multirow{6}{*}{$<0.001$} & a vs $b<0.001$ \\
\hline & & & & & & a vs $c<0.001$ \\
\hline & & & & & & a vs $d<0.001$ \\
\hline & & & & & & b vs $c<0.001$ \\
\hline & & & & & & b vs $d<0.001$ \\
\hline & & & & & & c vs $d<0.001$ \\
\hline \multirow{6}{*}{$\begin{array}{l}\text { Urinary NGAL/creatinine (ng/ } \\
\text { mg) }\end{array}$} & \multirow{6}{*}{$5.9(4.2,9.9)$} & \multirow{6}{*}{$12.4(10.3,15.5)$} & \multirow{6}{*}{$8.9(7.2,12.2)$} & \multirow{6}{*}{$24.6(18.9,31.1)$} & \multirow{6}{*}{$<0.001$} & a vs $b=0.001$ \\
\hline & & & & & & a vs $c<0.001$ \\
\hline & & & & & & a vs $d<0.001$ \\
\hline & & & & & & b vs $c<0.001$ \\
\hline & & & & & & b vs $d<0.001$ \\
\hline & & & & & & c vs $d<0.001$ \\
\hline
\end{tabular}

Note: $\mathrm{n}$ - Number of subjects, ${ }^{*}$ Data are median and inter quartile range in parentheses, ${ }^{* *}$ Kruskal-Wallis test, ${ }^{* *}$ Mann-Whitnay $\mathrm{U}$ test, SSNS-Steroid sensitive nephrotic syndrome, SRNS-Steroid resistant nephrotic syndrome.

Table 2: Duration of illness, urinary protein creatinine ratio, urinary creatinine, urinary NGAL, urinary NGAL/creatinine ratio in study subjects ( $n=80$ ).

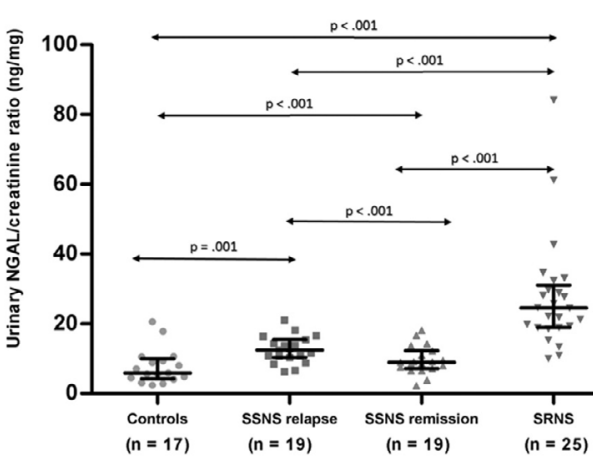

Figure 1: Urinary NGAL/creatinine values in study subjects. (n- number of cases, long horizontal lines indicate medians and short lines as interquartile ranges, SSNS- steroid sensitive nephrotic syndrome, SRNS- steroid resistant nephrotic syndrome)

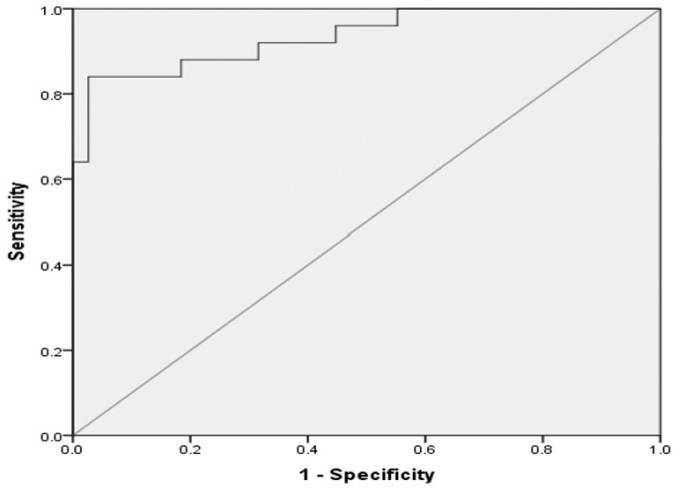

Figure 2: Receiver operating characteristic curve of urinary NGAL/ creatinine ratio for identification of SRNS. generated for urinary NGAL/creatinine to differentiate between SRNS from SSNS and a cut-off level of $>18.3 \mathrm{ng} / \mathrm{mg}$ had sensitivity of $84 \%$ and specificity of $97.4 \%$ with area under the curve of $0.935(\mathrm{p}<0.001,95 \%$ confidence interval 0.871-0.998) for identification of SRNS (Figure 2).

All cases of SRNS were subjected to renal biopsy and 12 had FSGS and 13 patients had MCD. The median urine protein creatinine ratio (35.5, interquartile range (IQR) $22.8,40.3$ vs 15.1 , IQR $8.0,23.8$, $\mathrm{p}=0.008)$, NGAL $(25.8$, IQR 22.8, 34.6 vs 18.8 , IQR $14.9,19.9, \mathrm{p}<0.001)$ and NGAL/creatinine ratios (28.5, IQR $23.1,34.2$ vs 18.9 , IQR 14.4, $24.6, p=0.003$ (Figure 3 ) were significantly raised in children with FSGS as compared to $\mathrm{MCD}$, respectively.

The Spearman's rho correlation coefficients of urinary NGAL/ creatinine ratio with duration of illness, eGFR, urine protein/creatinine ratio, serum total protein, albumin and cholesterol in cases of idiopathic nephrotic syndrome were calculated, and it had significant positive correlations with duration of illness $(\mathrm{r}=0.342, \mathrm{p}=0.006)$, urine protein creatinine ratio $(\mathrm{r}=0.594, \mathrm{p}<0.001)$ and serum cholesterol $(\mathrm{r}=0.440$, $\mathrm{p}<0.001)$, and negative correlations with serum total protein $(\mathrm{r}=-0.438$, $\mathrm{p}<0.001)$ and albumin $(\mathrm{r}=-0.470, \mathrm{p}<0.001)$.

\section{Discussion}

In the present study, the levels of both urinary NGAL and NGAL/ urinary creatinine levels were significantly higher in SRNS and SSNS relapse than other groups. Further, significantly higher median values were detected in SRNS as compared to SSNS relapse. Recently, other workers [8-10] have also reported significantly higher levels of urinary NGAL/creatinine in SRNS as compared to SSNS. Further, we found that a cut-off level of $18.34 \mathrm{ng} / \mathrm{mg}$ of NGAL/creatinine had sensitivity of $84 \%$ and specificity of $97.4 \%$ with AUC of 0.935 to differentiate SRNS patients from SSNS. This finding is consistent with the observations of Bennett et al. [8] in which they reported NGAL/creatinine ratio had a high power to distinguish SRNS from SSNS. Their ROC analysis 
Citation: Mishra OP, Mehta SK, Srivastava P, Abhinay A, Prasad R, et al. (2018) Urinary Neutrophil Gelatinase- Associated Lipocalin in Children with Idiopathic Nephrotic Syndrome: A Biomarker to Differentiate Between Steroid Sensitive and Resistant Forms of Disease. J Mol Biomark Diagn 9: 383. doi: 10.4172/2155-9929.1000383

Page 4 of 5

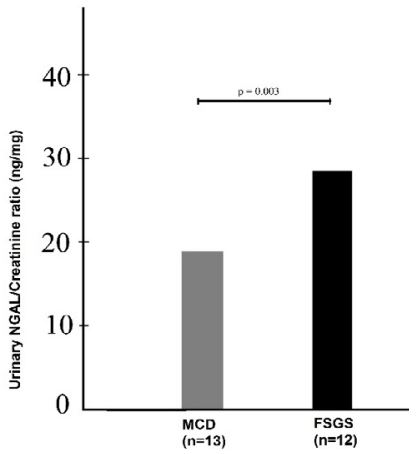

Figure 3: Bar diagrams showing median urinary NGAL/creatinine values in biopsy proven MCD and FSGS ( $n$ - number of cases, MCD- minimal change disease, FSGS- focal segmental glomerulosclerosis).

revealed an AUC of 0.91 for the detection of SRNS at cut-off value was $15 \mathrm{ng} / \mathrm{mg} \mathrm{NGAL} /$ creatinine with sensitivity and specificity of $88 \%$ each. Nickavar et al. [11] reported lower sensitivity $(62.96 \%)$ and AUC (0.7593) and almost similar specificity (92\%) for the diagnosis of SRNS. Bennett et al. [12] recently reported that a subset of 5 markers (NGAL, vitamin D binding protein, fetuin-A, prealbumin, and alpha-1 acid glycoprotein 2) showed significant associations with SRNS and yielded an AUC of 0.85 . The present study further confirms the utility of NGAL as a reliable biomarker to differentiate between SRNS and SSNS in children.

\section{Conclusion}

It is evident in our study that as such SRNS group had significantly longer duration of illness and higher median urine protein/creatinine ratio than SSNS. Higher values of proteinuria in SRNS have been also reported by Valles et al. [16] and Mishra et al. [17]. On further analysis it was found that median level of NGAL/creatinine was significantly higher in FSGS as compared to MCD in SRNS group and this is consistent with the findings of Bazzi et al. [18]. Youssef et al. [13] reported higher level of urinary NGAL in FSGS than controls. However, no significant difference in NGAL levels were found between FSGS and MCD cases reported by other authors [11,19] and this could be that there were smaller number of renal biopsy cases in their studies. Thus, patients of FSGS had unremitting heavy proteinuria and increased level of NGAL/creatinine level than MCD indicating more tubular injury in these patients.

The urinary NGAL/creatinine had significant positive correlations with duration of illness, urine protein creatinine ratio and serum cholesterol and negative correlations with serum total protein and albumin. Previous studies [7,9] also reported that urinary NGAL/ creatinine had significant correlation with urine protein creatinine ratio. By contrast, other authors did not find any correlation between the two parameters [8]. However, the positive relationship of NGAL/ creatinine with degree of proteinuria further explains effect of proteinuria on tubules and rise in NGAL due to tubular dysfunction. We did not find any correlation of urinary NGAL/creatinine ratio with eGFR. This was probably because none of our study patients had renal dysfunction. In contrast, previous studies $[7,8]$ had reported significant negative correlation of urinary NGAL/creatinine ratio with eGFR. This was probably due to significant derangement of renal function in their study subjects. Further it is supported by the fact that mean creatinine level found by Bennett et al. [8] in SRNS patients was $1.62 \mathrm{mg} / \mathrm{dl}$. One of the limitations of study is that there were smaller number of cases in FSGS and MCD. However, present observation of urinary NGAL/ creatinine has shown a definite difference in the level of this biomarker between these two different forms of histopathological lesions of SRNS. In conclusion, NGAL/creatinine can distinguish not only SRNS from SSNS patients, but also FSGS and MCD lesions of steroid resistant idiopathic nephrotic syndrome, which had different response to immunosuppressive therapy and long-term outcome in terms of renal survival [20].

\section{Funding}

The study was supported by the Institutional Grants of Department of Pediatrics, Institute of Medical Sciences and School of Biochemical Engineering Indian Institute of Technology, Banaras Hindu University, Varanasi, India.

\section{Author's contributions}

OPM, SKM, and RP involved in the study design, conduction, data analysis and drafting of manuscript, AA - helped in data analysis and drafting of manuscript PS performed the assay of NGAL and VVB examined the histopathology of renal tissues.

\section{Ethical approval}

All procedures performed in this study were in accordance with the ethical standards of the institutional ethical committee and with the 1964 Helsinki declaration and its later amendments.

\section{References}

1. Eddy AA, Symons JM (2009) Nephrotic syndrome in childhood. Lancet 362 629-639.

2. Mishra J, Ma Q, Prada A, Mitsnefes M, Zahedi K, et al. (2003) Identification of neutrophil gelatinase-associated lipocalin as a novel early urinary biomarker for ischemic renal injury. J Am Soc Nephrol 14: 2534-2543.

3. Mishra J, Ma Q, Kelly C, Mitsnefes M, Mori K, et al. (2006) Kidney NGAL is a novel early marker of acute injury following transplantation. Pediatr Nephrol 21: 856-863.

4. Trachtman H, Christen E, Cnaan A, Patrick J, Mai V, et al (2006) Urinary neutrophil gelatinase-associated lipocalcin in D+HUS: a novel marker of renal injury. Pediatr Nephrol 21: 989-994.

5. Bennett M, Dent CL, Ma Q, Dastrala S, Grenier F, et al. (2008) Urine NGAL predicts severity of acute kidney injury after cardiac surgery: a prospective study. Clin J Am Soc Nephrol 3: 665-673.

6. Bolignano D, Lacquaniti A, Coppolino G, Donato V, Campo S, et al. (2009) Neutrophil gelatinase- associated lipocalin and progression of chronic kidney disease. Clin J am Soc Nephrol 4: 337-344.

7. Nishida M, Kawakatsu H, Okumura Y, Hamaoka K (2010) Serum and urinary neutrophil gelatinase-associated lipocalin levels in children with chronic renal diseases. Pediatr Int 52: 563-568

8. Bennett MR, Piyaphanee N, Czech K, Mitsnefes M, Devarajan P (2012) NGAL distinguishes steroid sensitivity in idiopathic nephrotic syndrome. Pediatr Nephrol 27: 807-812.

9. Xia H, He QN, Li XY, Shuai LJ, Chen HX, et al. (2013) Expression of urinary neutrophi gelatinase-associated lipocalin and its clinical significance in children with idiopathic nephrotic syndrome. Zhongguo Dang Dai Er Ke Za Zhi. 15: 541-545.

10. Bieniaś B, Zajaczkowska M, Borzecka H, Sikora P, Wieczorkiewicz-Płaza A, et al. (2015) Early markers of tubulointerstitial fibrosis in children with idiopathic nephrotic syndrome: Preliminary report. Medicine (Baltimore) 94: e1746.

11. Nickavar A, Safaeian B, Sadeghi-Bojd S, Dashti LH (2016) Urine neutrophil gelatinase associated lipocalin to creatinine ratio: A novel index for steroid response in idiopathic nephrotic syndrome. Indian J Pediatr 83: 18-21.

12. Bennett MR, Pleasant L, Haffner C, Ma Q, Haffey WD, et al. (2017) A nove biomarker panel to identify steroid resistance in childhood idiopathic nephrotic syndrome. Biomark Insights.

13. Youssef DM, El-Shal AA (2012) Urine neutrophil gelatinase-associated lipocalin and kidney injury in children with focal segmental glomerulosclerosis. Iran J Kidney Dis 6: 355-360.

14. Management of steroid sensitive nephrotic syndrome: revised guidelines (2008) Indian Pediatric Nephrology Group, Indian academy of Pediatrics. Indian Pediatr 45: 203-214. 
Citation: Mishra OP, Mehta SK, Srivastava P, Abhinay A, Prasad R, et al. (2018) Urinary Neutrophil Gelatinase- Associated Lipocalin in Children with Idiopathic Nephrotic Syndrome: A Biomarker to Differentiate Between Steroid Sensitive and Resistant Forms of Disease. J Mol Biomark Diagn 9: 383. doi: 10.4172/2155-9929.1000383

15. Gulati A, Bagga A, Gulati S, Mehta KP, Vijayakumar M (2009) Indian Society of Pediatric Nephrology. Management of steroid resistant nephrotic syndrome. Indian Pediatr 46: 35-47.

16. Valles P, Peralta M, Carrizol L, Principi I, Gonzalez A, et al. (2000) Follow up of steroid resistant nephrotic syndrome:tubular proteinuria and enzymuria. Pediatr Nephrol 15: 252-258.

17. Mishra OP, Jain P, Srivastava P, Prasad R (2012) Urinary N-acetyl -beta-Dglucosaminidase(NAG) level in idiopathic nephritic syndrome. Pediatr Nephrol 27: 589-596.
18. Bazzi C, Petrini C, Rizza V, Arrigo G, Napodano P, et al. (2003) Urinary $\mathrm{N}$-acetyl-beta-glucasaminidase excretion is a marker of tubular cell dysfunction and a predictor of outcome in primary glomerulonephritis. Nephrol Dial Transplant 17: 1890-1896

19. Korzeniecka-Kozerska A, Wasilewska A, Tenderenda E, Sulik A, Cybulski K (2013) Urinary MMP-9/NGAL ratio as a potential marker of FSGS in nephrotic children. Dis Markers 34: 357-362.

20. Trautmann A, Schnaidt S, Lipska-Ziętkiewicz BS, Bodria M, Ozaltin F, et al. (2017) Long-term outcome of steroid-resistant nephrotic syndrome in children J Am Soc Nephrol 28: 3055-3065. 